\title{
Ethanol-Induced Motor Impairment Mediated by Inhibition of $\alpha 7$ Nicotinic Receptors
}

\author{
[Dohn McDaid, ${ }^{1}$ Chandrika Abburi, ${ }^{1}$ Shannon L. Wolfman, ${ }^{2}$ Keith Gallagher, ${ }^{1}$ and ${ }^{\circ D a n i e l ~ S . ~ M c G e h e e ~}{ }^{1,2}$ \\ ${ }^{1}$ Department of Anesthesia and Critical Care and ${ }^{2}$ Committee on Neurobiology, University of Chicago, Chicago, Illinois 60637
}

\begin{abstract}
Nicotine and ethanol (EtOH) are among the most widely co-abused substances, and nicotinic acetylcholine receptors (nAChRs) contribute to the behavioral effects of both drugs. Along with their role in addiction, nAChRs also contribute to motor control circuitry. The $\alpha 7$ nAChR subtype is highly expressed in the laterodorsal tegmental nucleus (LDTg), a brainstem cholinergic center that contributes to motor performance through its projections to thalamic motor relay centers, including the mediodorsal thalamus. We demonstrate that $\mathrm{EtOH}$ concentrations just above the legal limits for intoxication in humans can inhibit $\alpha 7 \mathrm{nAChRs}$ in LDTg neurons from rats. This EtOH-induced inhibition is mediated by a decrease in cAMP/PKA signaling. The $\alpha 7 \mathrm{nAChR}$-positive allosteric modulator PNU120596 [ $N$-(5-chloro-2,4-dimethoxyphenyl)- $N^{\prime}$-(5-methyl-3-isoxazolyl)-urea], which interferes with receptor desensitization, completely eliminated EtOH modulation of these receptors. These data suggest that EtOH inhibits $\alpha 7$ responses through a PKA-dependent enhancement of receptor desensitization. EtOH also inhibited the effects of nicotine at presynaptic $\alpha 7 \mathrm{nAChRs}$ on glutamate terminals in the mediodorsal thalamus. In vivo administration of PNU120596 either into the cerebral ventricles or directly into the mediodorsal thalamus attenuated EtOH-induced motor impairment. Thus, $\alpha 7 \mathrm{nAChRs}$ are likely important mediators of the motor impairing effects of moderate $\mathrm{EtOH}$ consumption.
\end{abstract}

Key words: aversion; ethanol; motor impairment; nicotine; protein kinase A; rotarod

Significance Statement

The motor-impairing effects of ethanol contribute to intoxication-related injury and death. Here we explore the cellular and neural circuit mechanisms underlying ethanol-induced motor impairment. Physiologically relevant concentrations of ethanol inhibit activity of a nicotinic receptor subtype that is expressed in brain areas associated with motor control. That receptor inhibition is mediated by decreased receptor phosphorylation, suggesting an indirect modulation of cell signaling pathways to achieve the physiological effects.

\section{Introduction}

Nicotine and ethanol (EtOH) are the most commonly co-abused drugs (Miller and Gold, 1998), and addiction to either increases the likelihood of addiction to the other (CASA, 2007). EtOHinduced sedative/motor impairment effects are reduced by coadministration of nicotine (O'Brien et al., 2008), which may contribute to the nicotine-induced enhancement of EtOH selfadministration in both animal and human subjects (Blomqvist et al., 1996; Barrett et al., 2006). A single injection of nicotine into

\footnotetext{
Received Jan. 14, 2016; revised June 3, 2016; accepted June 7, 2016.

Author contributions: J.M. and D.S.M. designed research; J.M., C.A., S.L.W., and K.G. performed research; J.M., C.A., S.L.W., K.G., and D.S.M. analyzed data; J.M., C.A., S.L.W., and D.S.M. wrote the paper.

This work was supported by National Institutes of Health Grants AA020082 (J.M. and D.S.M.), DA019695 and DA036978 (D.S.M.), and DA07255 (S.L.W.).

The authors declare no competing financial interests.

Correspondence should be addressed to Daniel McGehee, Department of Anesthesia and Critical Care, University of Chicago, 5841 South Maryland Avenue, MC4028, Chicago, IL 60637. E-mail: dmcgehee@uchicago.edu.

DOI:10.1523/JNEUROSCI.0154-16.2016

Copyright $\odot 2016$ the authors $\quad 0270-6474 / 16 / 367768-11 \$ 15.00 / 0$
}

the cerebellum decreases EtOH impairment of rotarod performance (Al-Rejaie and Dar, 2006), and $\alpha 7$ nicotinic acetylcholine receptor (nAChR) knock-out mice display altered sensitivity to EtOH-induced locomotor effects relative to wild-type mice (Bowers et al., 2005). These studies suggest that $\alpha 7 \mathrm{nAChRs}$ are important mediators of EtOH-induced motor impairment.

The high $\mathrm{Ca}^{2+}$ permeability of $\alpha 7$ receptors make them ideal modulators of $\mathrm{Ca}^{2+}$-dependent cellular events, including neurotransmitter release (Séguéla et al., 1993; McGehee et al., 1995; Radcliffe et al., 1999; Jiang and Role, 2008). Activation of presynaptic $\alpha 7 \mathrm{nAChRs}$ enhances excitatory neurotransmission and facilitates LTP induction in several brain areas (Mansvelder and McGehee, 2000; Welsby et al., 2006). Cholinergic activation of postsynaptic $\alpha 7 \mathrm{nAChRs}$ can mediate excitatory synaptic transmission in hippocampus and cerebral cortex (Frazier et al., 1998; Bennet et al., 2012). These studies suggest that $\alpha 7 \mathrm{nAChRs}$ influence CNS function, which likely affects behavior. Indeed, systemic administration of selective $\alpha 7 \mathrm{nAChR}$ antagonists decreases indices of locomotion and motor coordination (Marks et 
al., 1983; Kempsill and Pratt, 2000; Chilton et al., 2004; Welch et al., 2013). EtOH has been shown to inhibit $\alpha 7$ nAChRs in cultured cortical neurons and Xenopus oocytes (Yu et al., 1996; Covernton and Connolly, 1997; Aistrup et al., 1999; Cardoso et al., 1999; Oz et al., 2005; Ishibashi et al., 2009). Together, these observations lead us to explore the cellular mechanisms linking $\alpha 7$ nAChRs to the motor-impairing effects of EtOH.

To test this idea, we targeted the laterodorsal tegmental nucleus (LDTg), a brainstem cholinergic center that contributes to a variety of functions, including motor control (Laviolette et al., 2000; Kayama and Koyama, 2003; Alderson et al., 2005; Maskos, 2008). A subset of LDTg neurons express mRNA encoding the $\alpha 7$ nAChR subunit (Azam et al., 2003). Using brain slice electrophysiology, we assayed $\alpha 7$ currents in LDTg neurons and examined the mechanisms underlying EtOH modulation of these receptors. We then investigated the contribution of this modulation to EtOH-induced motor impairment.

\section{Materials and Methods}

Animals. Adult male Sprague Dawley rats (P60-P90) were housed two per cage, except after surgeries when they were singly housed to facilitate recovery, on a $12 \mathrm{~h}$ reverse light/dark cycle with ad libitum access to food and water. All animal procedures used were approved by the University of Chicago Institutional Animal Care and Use Committee.

Electrophysiology. After induction of anesthesia with isoflurane, animals were decapitated and their brains removed to ice-cold sucrose artificial CSF [aCSF; in mM: 125 sucrose, $2.5 \mathrm{KCl}, 1 \mathrm{MgCl}_{2}, 2.5 \mathrm{CaCl}_{2}, 20$ glucose, $1 \mathrm{NaH}_{2} \mathrm{PO}_{4}, 25 \mathrm{NaHCO}_{3}$, and 10 ascorbic acid (bubbled continuously with $\left.95 \% \mathrm{O}_{2} / 5 \% \mathrm{CO}_{2}\right)$ ]. Parasagittal slices were cut $(250 \mu \mathrm{m}$; VT1000S; Leica) containing the LDTg and incubated in normal aCSF [in mм: $125 \mathrm{NaCl}, 2.5 \mathrm{KCl}, 1 \mathrm{MgCl}_{2}, 2.5 \mathrm{CaCl}_{2}, 20$ glucose, $1 \mathrm{NaH}_{2} \mathrm{PO}_{4}, 25$ $\mathrm{NaHCO}_{3}$, and 1 ascorbic acid (bubbled with $95 \% \mathrm{O}_{2} / 5 \% \mathrm{CO}_{2}$; perfused at $\left.\left.20 \mathrm{~mL} / \mathrm{min} ; 34^{\circ} \mathrm{C}\right)\right]$. Slices were transferred to a recording chamber and superfused with normal aCSF without ascorbic acid $\left(2 \mathrm{ml} / \mathrm{min} ; 32^{\circ} \mathrm{C}\right)$. The location of the LDTg or mediodorsal (MD) thalamus was identified according to anatomical boundaries, and LDTg neurons were visualized under infrared illumination using an upright microscope (Axioskop; Zeiss; Paxinos and Watson, 1998). Whole-cell voltage-clamp recordings used an Axopatch 200B amplifier, a Digidata 1200 interface, and pClamp 8 (Molecular Devices), and data were filtered at $1 \mathrm{kHz}$ and digitized at 5 $\mathrm{kHz}, V_{\mathrm{m}}=-70 \mathrm{mV}$. Borosilicate electrodes were pulled to a resistance of 3-7 $\mathrm{M} \Omega$ and contained a recording solution (in $\mathrm{mM}$ ): $154 \mathrm{~K}$-gluconate, 1 $\mathrm{KCl}, 1$ EGTA, 10 HEPES, 10 glucose, and 5 ATP, pH 7.4 with KOH. Series resistance was $<20 \mathrm{M} \Omega$. Rapid focal application of ACh was performed using a Picospritzer II (General Valve). Two separate pipettes, one containing ACh (1 mM) in aCSF and another containing an identical concentration of $\mathrm{ACh}$ mixed with $\mathrm{EtOH}$ (at the concentration that was bath applied), were positioned $\sim 50 \mu \mathrm{m}$ from the recorded neuron. $\alpha 7$ nAChR currents in LDTg neurons displayed a rapid onset $(>100 \mathrm{~ms}$ time-to-peak) and rapid desensitization Experiments were conducted in the presence of $10 \mu \mathrm{M}$ DNQX, $20 \mu \mathrm{M}$ bicuculline, and $1 \mu \mathrm{M}$ atropine to limit indirect effects from synaptic inputs or muscarinic AChRs. ACh applications of $300 \mathrm{~ms}$ duration were tested at one min intervals. After obtaining consistent peak inward current responses to successive ACh applications (see Fig. $2 A$ ), EtOH at the test concentration was perfused over the slice for $10 \mathrm{~min}$. During that time, ACh plus $\mathrm{EtOH}$ focal applications were tested at 5 and $10 \mathrm{~min}$ time points. After washout of EtOH, $\mathrm{ACh}$ currents were monitored for at least another $10 \mathrm{~min}$ to assess the extent of recovery. In a subset of the recordings, the $\alpha 7 \mathrm{nAChR}$ antagonist methyllycaconitine (MLA; $10 \mathrm{nM}$ ) was bath applied to confirm identification of the nAChR. Only one cell per slice was tested. When investigating the role of PKA in the effects of EtOH, the recording pipettes contained either the PKA inhibitor Rp-cAMPs or the PKA activator Sp-cAMPs, at concentrations of $100 \mu \mathrm{M}$ and $1 \mathrm{mM}$, respectively. For tests of the direct effect of either Rp-cAMPs or Sp-cAMPs on the $\alpha 7$ current in the absence of $\mathrm{EtOH}, \mathrm{ACh}$ was applied once every minute for up to $20 \mathrm{~min}$. Testing modulation of synaptic inputs to MD thalamus used the same parasagittal slice preparation and recording conditions as with the LDTg. The external solution included $20 \mu \mathrm{M}$ bicuculline to block $\mathrm{GABA}_{\mathrm{A}}$ receptors and $1 \mu \mathrm{M}$ TTX to block voltage-gated Na channels. This allowed for the observation of miniature EPSCs.

Immunohistochemistry. To identify cell types in the LDTg, $0.1 \%$ biocytin was included in the internal recording solution. After recording, slices were fixed in $4 \%$ paraformaldehyde and $15 \%$ saturated picric acid in $0.2 \mathrm{M}$ phosphate buffer at $4^{\circ} \mathrm{C}(3 \mathrm{~h})$ and then placed in $0.05 \mathrm{M}$ Trisbuffered saline (TBS), $\mathrm{pH} \mathrm{7.4,} \mathrm{at} 4^{\circ} \mathrm{C}$ until processing. Slices were permeabilized with a $1 \%$ sodium borohydride $(30 \mathrm{~min})$ treatment and rinsed three times with TBS and four times with TBS plus $1 \%$ normal goat serum (NGS). Slices were then treated with TBS plus 3\% NGS plus $1 \%$ Triton X-100 (60 min) and incubated with rabbit anti-choline acetyltransferase (Millipore Bioscience Research Reagents) diluted at 1:100 in TBS containing $1 \%$ NGS and $1 \%$ Triton X-100 at $4^{\circ} \mathrm{C}(5 \mathrm{~d})$. After rinses in TBS containing $1 \%$ NGS (five times for $15 \mathrm{~min}$ ), slices were incubated in Alexa Fluor 488 goat anti-rabbit diluted at 1:100 and Cy3-conjugated streptavidin (Jackson ImmunoResearch) diluted at 1:500 in TBS containing $1 \%$ NGS and $1 \%$ Triton X-100 at room temperature $(2 \mathrm{~h})$. After additional rinses in TBS containing 1\% NGS (five times for $15 \mathrm{~min}$ ), slices were slide mounted for microscopy. Omission of the primary antibody was used in control slices to assess specificity of the staining.

Survival surgery. For surgeries involving intracerebroventricular or MD thalamic cannulations, animals were anesthetized with a combination of ketamine $(100 \mathrm{mg} / \mathrm{kg}$, i.p. $)$ and xylazine $(10 \mathrm{mg} / \mathrm{kg}$, i.p. $)$ and placed in a stereotaxic frame. For intracerebroventricular injection, guide cannulae were positioned into the right lateral ventricle $(-0.8 \mathrm{~mm}$ anteroposterior, $+1.4 \mathrm{~mm}$ lateral, $-3.0 \mathrm{~mm}$ dorsoventral from Bregma). For MD thalamic cannulation, the guide cannula was placed $15^{\circ}$ to vertical at $-2.8 \mathrm{~mm}$ anteroposterior, $+1.6 \mathrm{~mm}$ lateral, and $5.5 \mathrm{~mm}$ dorsoventral from Bregma. All guide cannulae were secured with dental acrylic. Animals recovered for at least $3 \mathrm{~d}$ before rotarod training.

Rotarod testing. On training day, the animals were placed on the rotarod (Rotamex 5; Columbus Instruments) at a fixed speed of $4 \mathrm{rpm}$. Once all animals in that cohort demonstrated an ability to remain on the rotarod at $4 \mathrm{rpm}$ for $\sim 10 \mathrm{~s}$, the speed was increased at a rate of $1 \mathrm{rpm}$ every $5 \mathrm{~s}$ until the last animal fell off. Animals that fell remained in chambers beneath the rotarod until the end of the trial. This protocol was repeated for a total of 10 consecutive trials after which the animals were returned to their home cages. Three days later, animals were tested for the effects of $\mathrm{EtOH}$ on rotarod performance. First, baseline performance on the accelerating rotarod was assessed over four consecutive trials. After completion of the baseline assessment, either PNU120596 [ $N$-(5-chloro2,4-dimethoxyphenyl)- $N^{\prime}$-(5-methyl-3-isoxazolyl)-urea] (100 $\mu \mathrm{M}$ in aCSF with $2 \%$ DMSO and $5 \%$ cyclodextrin) or vehicle was focally injected. For intracerebroventricular administration, $20 \mu \mathrm{l}$ of either the drug or vehicle was injected over a 1 min period. For intra-MD thalamic injection, $1 \mu \mathrm{l}$ of either solution was injected over a $1 \mathrm{~min}$ period. Animals were injected $15 \mathrm{~min}$ later with $1 \mathrm{~g} / \mathrm{kg}$ EtOH intraperitoneally ( $50 \%$ in PBS) or PBS alone. After another $15 \mathrm{~min}$, the effects of EtOH on rotarod performance were tested in six sets of four consecutive trials at 15 min intervals. After the conclusion of testing, colored dye was injected intracerebroventricularly or intra-MD thalamic, and the animals were killed. Brain slices were taken to confirm that the dye was present in the ventricles or MD thalamus, respectively, to verify cannula placement.

Immunoblotting. Animals were treated with $1 \mathrm{~g} / \mathrm{kg}$ EtOH intraperitoneally (50\% in PBS) or PBS and killed 15 min later. Brains were rapidly removed, and the LDTg was dissected out and homogenized using a Dounce homogenizer in $400 \mu \mathrm{l}$ of an ice-cold lysis buffer (containing 25 mм HEPES, 150 mм NaCl, 2 mм EDTA, 20 mm NaF, 0.1\% v/v Nonidet P-40, $1 \mathrm{~mm}$ PMSF, a protease, and phosphatase inhibitor mixture). Homogenates were then sonicated, mixed with an SDS-containing sample buffer and sample-reducing agent (Invitrogen), and heated at $70^{\circ} \mathrm{C}$ for 10 $\mathrm{min}$. For the immunoprecipitation procedure, samples were incubated with IgG-coated beads (Dynabeads; Invitrogen) that were complexed with a rabbit anti- $\alpha 7 \mathrm{nAChR}$ antibody (ab-10096; Abcam). The immunoprecipitated protein was separated from the beads using an elution buffer (Piercenet). Samples were again mixed with sample buffer and sample-reducing agent and stored at $-80^{\circ} \mathrm{C}$ overnight. Samples were 
A

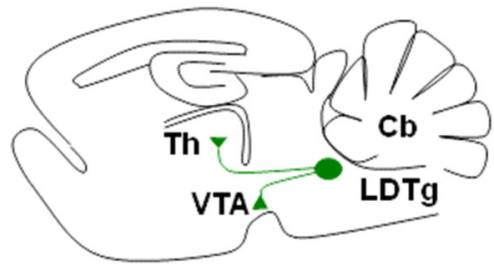

B

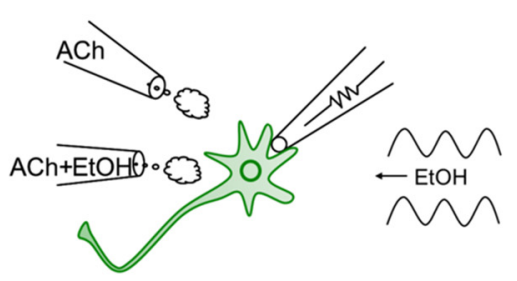

C $\underline{A C h}$

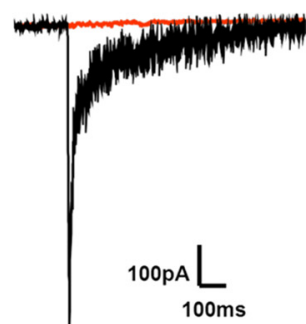

D
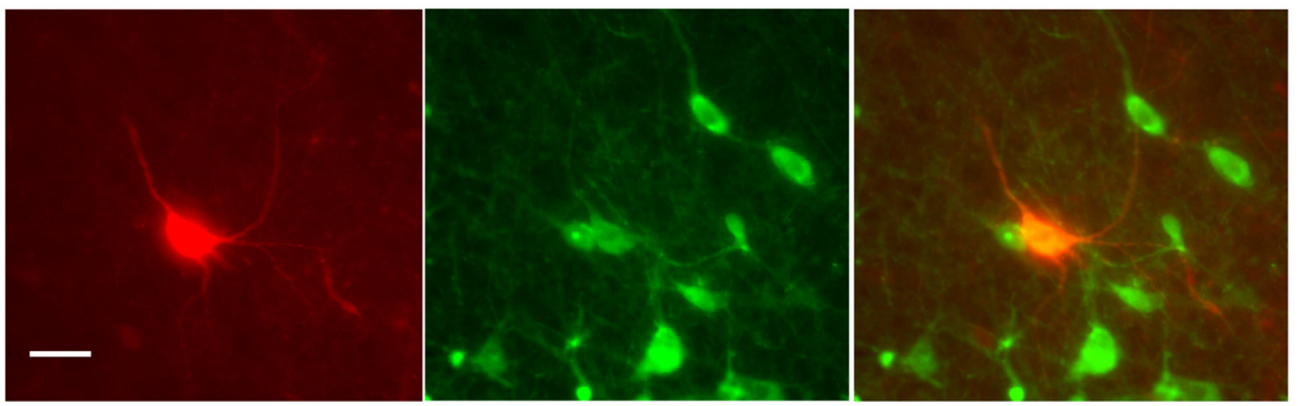

Figure 1. Cholinergic neurons in the LDTg express $\alpha 7 \mathrm{nAChRs.} A$, Parasagittal view of the rat brain, illustrating LDTg cholinergic neurons that project to the thalamus and VTA. $\boldsymbol{B}$, Experimental design consisting of two puffer pipettes, one containing $\mathrm{ACh}$ and the other a mixture of $\mathrm{ACh}$ and EtOH; focal application of ACh or ACh plus EtOH was performed in conjunction with bath application of EtOH. C, Sample trace of an inward current resulting from focal ACh application $\left(1 \mathrm{~mm}, 300 \mathrm{~ms}, V_{\mathrm{m}}=-70 \mathrm{mV}\right.$, bar denotes application). This current was completely blocked by bath application of the selective $\alpha 7 \mathrm{nAChR}$ antagonist MLA (10 nm, red trace). D, The recorded cell was loaded with biocytin ( $0.1 \%$, in red, left) and stained positive for ChAT (in green, middle); the composite image of the recorded cell shows costaining for biocytin and ChAT (in orange, right). Ten of 11 biocytin-labeled neurons, which expressed $\alpha 7 \mathrm{nAChR}$ current, were also positive for ChAT (scale bar, $25 \mu \mathrm{m}$ ).

subjected to SDS-PAGE on 4-20\% Mini-PROTEAN TGX precast polyacrylamide gels (Bio-Rad). Gels included a visible marker (precision plus; Bio-Rad) and a molecular weight marker (Magic Mark; Invitrogen). After electrophoresis ( $1 \mathrm{~h}$ at $200 \mathrm{~V}$ ), protein was transferred onto polyvinylidine difluoride membranes. After protein transfer, membranes were washed twice for $10 \mathrm{~min}$ in TBS with Tween (TBST; $25 \mathrm{~mm}$ Tris- $\mathrm{HCl}, \mathrm{pH} 7.4,140 \mathrm{~mm} \mathrm{NaCl}$, and $0.1 \%$ Tween 20 ) and then incubated for $1 \mathrm{~h}$ in TBST with $5 \%$ nonfat dry milk to reduce nonspecific binding of primary antibody. Membranes were washed and incubated overnight at $4^{\circ} \mathrm{C}$ in TBST with $5 \%$ milk containing either rabbit anti- $\alpha 7 \mathrm{nAChR}$ antibody (ab10096; 1:1000; Abcam) or rabbit anti-phosphoserine (ab9332; 1:1000; Abcam). After primary antibody incubation, membranes were washed and incubated with an alkaline phosphatase-conjugated antirabbit secondary antibody ( $1 \mathrm{~h}$ at room temperature; Invitrogen). After two more TBST washes, membranes were treated with a chemiluminescent substrate for alkaline phosphatase (Immunstar; Bio-Rad), and luminescent membranes were exposed to photographic film (Kodak Biomax Light) until sufficient immunoreactivity was visualized. Immunoreactive bands corresponding to the molecular weight of the proteins were scanned and quantified using UN-SCAN-IT software (Silk Scientific). The relative phosphorylation state of the $\alpha 7 \mathrm{nAChR}$ was quantified by dividing the total pixel density of the band for phosphoserine by the corresponding band for $\alpha 7 \mathrm{nAChR}$ from a separate membrane. This ratio was then normalized to the average for the PBS control group.

Data analysis and statistics. $\alpha 7 \mathrm{nAChR}$ currents were analyzed using Clampfit (Molecular Devices) and MiniAnalysis (Synaptosoft). The peak ACh currents were determined by the maximal inward current deflection during the $300 \mathrm{~ms}$ period when ACh was focally applied. The concentration-effect curve for EtOH modulation of $\alpha 7 \mathrm{nAChR}$ current was fit using the following Hill equation:

$$
y=1+\left(\mathrm{IC}_{50} / x\right)^{n H},
$$

in which $y$ is the current amplitude, $x$ is the $\mathrm{EtOH}$ concentration, $\mathrm{IC}_{50}$ is the EtOH concentration that inhibited the currents to $50 \%$ of the maximal inhibition, and $n H$ is the Hill coefficient. ANOVA was used to determine the main effects of EtOH on the $\alpha 7 \mathrm{nAChR}$ current, as well as the effects of blockers and PNU120596 on the $\alpha 7$ nAChR response modulation by EtOH. A post hoc Dunnett's test was used to assess effects between treatment groups and a designated control group. For analysis of behavior, we used a two-way repeated-measures (RM) ANOVA, followed by a Tukey's post hoc test. For immunoblotting, a Student's $t$ test was used to compare the normalized phosphoserine/ $\alpha 7 \mathrm{nAChR}$ ratio between $\mathrm{EtOH}$ and PBS treatment groups.

mEPSC data was analyzed using MiniAnalysis (Synaptosoft). Baseline frequency was calculated as the average of six $10 \mathrm{~s}$ bins before nicotine application. The nicotine effect was calculated as the average of the highest six consecutive bins obtained during nicotine application. This value was then calculated as a percentage of the baseline. Differences in frequency and amplitude cumulative distributions were assessed using the Kolmogorov-Smirnov (K-S) nonparametric test in MiniAnalysis.

All statistical tests were performed using MiniAnalysis or Sigmaplot (Systat Software). All results are presented as means \pm SEM.

\section{Results}

Cholinergic neurons in the LDTg have large-diameter somata, and, in parasagittal brain slices from adult rats, the relative lack of fibers of passage facilitates visualization of these neurons (Fig. $1 A)$. In whole-cell recordings, the majority of these cells ( $90 \%)$ responded to focal application of ACh (1 mM) with robust inward currents mediated by $\mathrm{nAChRs}$ that were almost exclusively of the $\alpha 7$ subtype (Fig. 1 B, $C ; 652.7 \pm 59.4 \mathrm{pA} ; n=45$ ). The rapid onset and decay kinetics in the continued presence of agonist are typical of $\alpha 7 \mathrm{nAChRs}$. Bath perfusion of the selective $\alpha 7 \mathrm{nAChR}$ antagonist MLA (10 nM) blocked these currents within minutes (Fig. $1 C)$. In a subset of experiments, biocytin $(0.01 \%)$ was included in the recording pipette to identify recorded cells. Immunocytochemistry revealed 10 of 11 biocytin-positive LDTg neurons colabeled for the cholinergic marker choline acetyltransferase (Fig. 1D). 

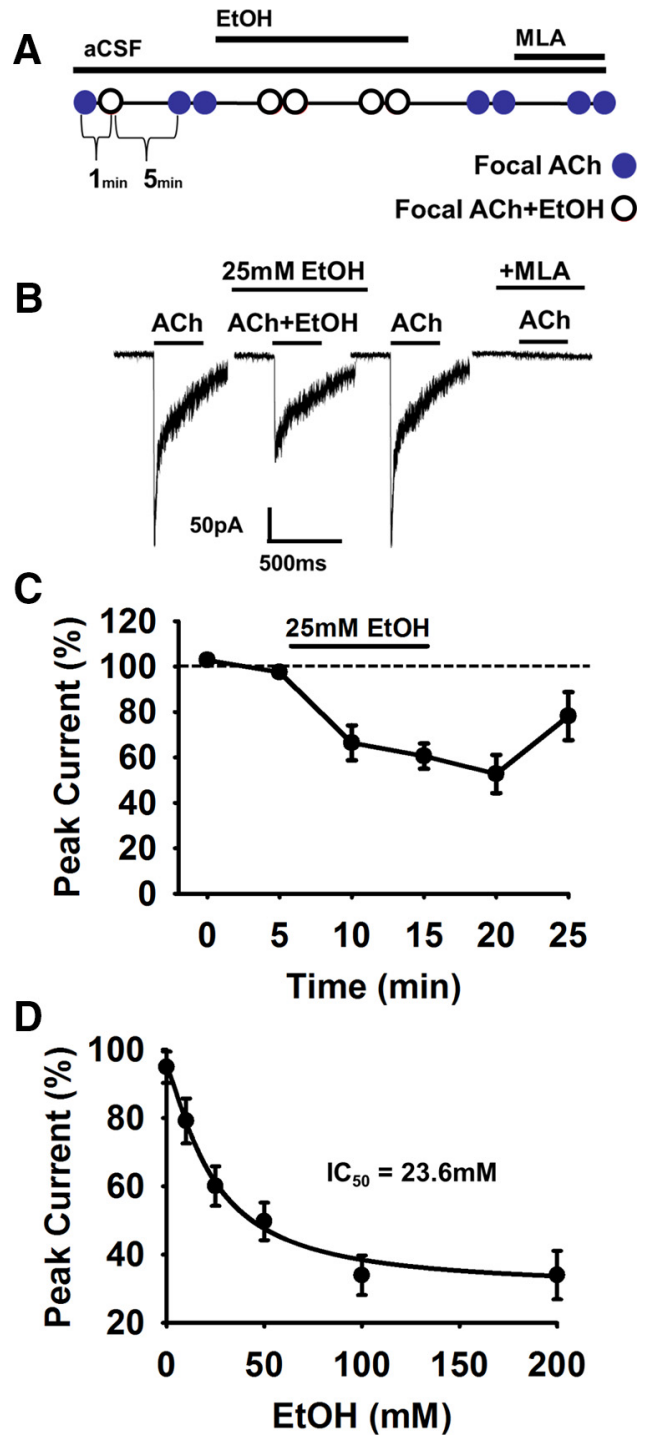

Figure 2. Et0H dose dependently inhibits $\alpha 7 \mathrm{nAChRs}$ in LDTg neurons. A, Diagram of experimental protocol: focal application of ACh $(300 \mathrm{~ms})$ was followed by focal application of a combination of ACh plus EtOH. After 5 min, ACh was again focally applied to ensure a consistent response. EtOH was then bath applied for $10 \mathrm{~min}$, and the responses to focal $\mathrm{ACh}$ plus EtOH were tested at $5 \mathrm{~min}$ intervals. This was followed by a washout period and then by bath application of the selective $\alpha 7 \mathrm{nAChR}$ antagonist MLA (10 nM) to confirm the nAChR subtype. During EtOH bath application, the response to $\mathrm{ACh}$ was tested using a pipette with $\mathrm{ACh}$ plus EtOH, to ensure that the $\mathrm{Et} O \mathrm{H}$ concentration remained constant. Repeatability and consistency of the responses were ensured by using the same pressure line for both puffer pipettes and by pulling both pipettes from the same piece of glass to yield similar resistance. Baseline ACh current was the average of the last two currents obtained before bath application of EtOH. EtOH effects were the average of the last two ACh plus EtOH currents before washout. B, Representative $\alpha 7 \mathrm{nAChR}$ currents recorded from an LDTg neuron during focal application of $A C h(1 \mathrm{mM})$ before, during, and after bath application of $25 \mathrm{~mm}$ EtOH. Note the reversal of the EtOH effect on washout. The ACh-evoked current was completely blocked by MLA (10 nM). C, Time course of the effects of bath application of $25 \mathrm{~mm}$ EtOH. D, Concentration- effect relationship for EtOH inhibition of peak $\alpha 7 \mathrm{nAChR}$ currents in LDTg neurons. The EtOH $\mathrm{IC}_{50}$ was $23.6 \mathrm{~mm}$, with a Hill coefficient of $-1.6 . V_{\mathrm{m}}=-70 \mathrm{mV}$ for all recordings. $n=4,7,11,15,5$, and 3 for $0,10,25,50,100$, and $200 \mathrm{~mm}$ EtOH, respectively. ANOVA $\left(F_{(5,44)}=7.7, p<0.001\right)$, post hoc test with all concentrations compared with aCSF vehicle.

\section{EtOH inhibition of $\alpha 7 \mathrm{nAChRs}$ in LDTg neurons}

To test the modulatory effects of EtOH on $\alpha 7 \mathrm{nAChRs} \mathrm{in} \mathrm{LDTg,}$ we used a within-cell comparison method (Fig. 2A). First, the neurons were tested for their response to a focal application of ACh (1 mM). As illustrated in Figure 2B, 10 min pretreatment of the slice with EtOH (25 mM) resulted in a profound suppression of nAChR currents. Subsequent blockade by MLA (10 nM) confirmed that the current was mediated by $\alpha 7 \mathrm{nAChRs}$. Time course of the effects of $25 \mathrm{~mm} \mathrm{EtOH}$ on these currents is illustrated in Figure $2 C$. In a subset of the experiments, the $\alpha 7 \mathrm{nAChR}$ currents recovered from inhibition after washout of $\mathrm{EtOH}$, indicating that the effects are reversible (Fig. $2 B, C$ ). Modulation of the $\mathrm{ACh}$ response was tested at $\mathrm{EtOH}$ concentrations between 10 and $200 \mathrm{~mm}$. Decreased ACh responses were seen at all EtOH concentrations tested $\left[\operatorname{ANOVA}\left(F_{(5,44)}=7.7, p<0.001\right)\right.$, post hoc test with all concentrations compared with aCSF vehicle]. Fitting the concentration-effect relationship revealed an $\mathrm{IC}_{50}$ for $\mathrm{EtOH}$ of $23.6 \mathrm{~mm}$ with a Hill coefficient of -1.6 (Fig. 2D). At the higher EtOH concentrations, a longer time course of recovery was observed (data not shown). EtOH modulation of $\alpha 7$ currents was highly prevalent, with significant inhibition in nearly every cell tested (39 of 45).

Interestingly, EtOH did not have rapid effects on ACh responses. In the absence of EtOH pretreatment, simultaneous application of $\mathrm{EtOH}$ and $\mathrm{ACh}$ were always within $5 \%$ of the responses to ACh alone, regardless of the $\mathrm{EtOH}$ concentration tested. For example, the average peak current in response to coapplication of ACh plus $50 \mathrm{~mm}$ EtOH was $101.9 \pm 1.3 \%$ of the response to ACh alone $(n=9)$. This suggests that EtOH modulates $\alpha 7 \mathrm{nAChRs}$ through a cell signaling mechanism in these neurons rather than a direct interaction with the receptor, as reported previously (Yu et al., 1996).

\section{Role of cAMP/PKA in EtOH inhibition of $\alpha 7 \mathrm{nAChRs}$}

Phosphorylation state can modulate ligand-gated ion channel function (Quik et al., 1997; Fenster et al., 1999; Swope et al., 1999; Di Angelantonio et al., 2011), and $\alpha 7$ nAChR subunits can undergo PKA-mediated phosphorylation (Moss et al., 1996). In addition, EtOH has been reported to affect cAMP/PKA signaling (Rabin and Molinoff, 1981; Nagy and DeSilva, 1992; Hellevuo et al., 1995; Yoshimura and Tabakoff, 1999). To explore the possible involvement of this pathway in EtOH modulation of $\alpha 7 \mathrm{nAChRs}$, we first tested whether modifying PKA activity in LDTg neurons could alter $\alpha 7$ responses. Neurons were pretreated with either the PKA inhibitor Rp-cAMPs $(100 \mu \mathrm{M})$ or the PKA activator Sp-cAMPs (1 mM) via the recording electrode internal solution, while $\alpha 7$ currents were monitored at 1 min intervals (Fig. $3 A-D$ ). As shown in the example traces and representative time course, inhibiting PKA decreased the $\alpha 7$ current amplitude, whereas activating the kinase enhanced the responses (Fig. 3A-C). Average changes in peak current are illustrated in Figure $3 D$.

To test the possible involvement of PKA signaling in EtOH modulation of $\alpha 7$ responses in LDTg neurons, we repeated the EtOH treatment protocol outlined in Figure 2 while including either Rp-cAMPs or Sp-cAMPs in the recording electrode. For these tests, EtOH application was initiated $10 \mathrm{~min}$ after wholecell recording was started to allow PKA modulation to stabilize. Interestingly, pretreatment with Rp-cAMPs to block PKA activity eliminated the effects of $25 \mathrm{~mm}$ EtOH on the peak $\alpha 7$ current (Fig. $3 E, F$ ). These data suggest that the EtOH-induced suppression of $\alpha 7$ responses is occluded by the inhibition of PKA activity in LDTg neurons. In contrast, although Sp-cAMPs treatment augmented $\alpha 7$ responses (Fig. $3 B-D$ ), $25 \mathrm{~mm}$ EtOH treatment reduced the responses under these conditions to a similar extent to EtOH treatment alone [ANOVA, $\left(F_{(2,20)}=18.9\right.$, post hoc tests), $p=0.45$ and ${ }^{* *} p<0.001$ for Sp-cAMPs and Rp-cAMPs vs $25 \mathrm{~mm} \mathrm{EtOH}$, respectively]. These results support a role for the PKA pathway in the modulation of $\alpha 7$ responses by EtOH. Inhi- 
A

$$
\text { Rp-cAMPs }
$$

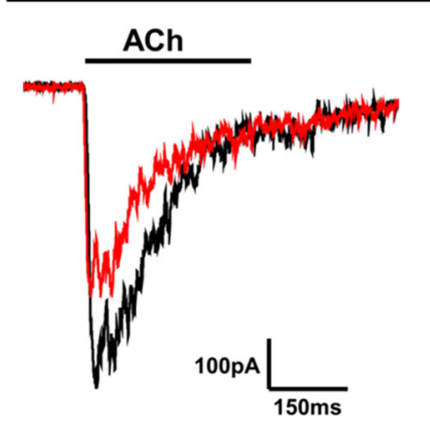

C

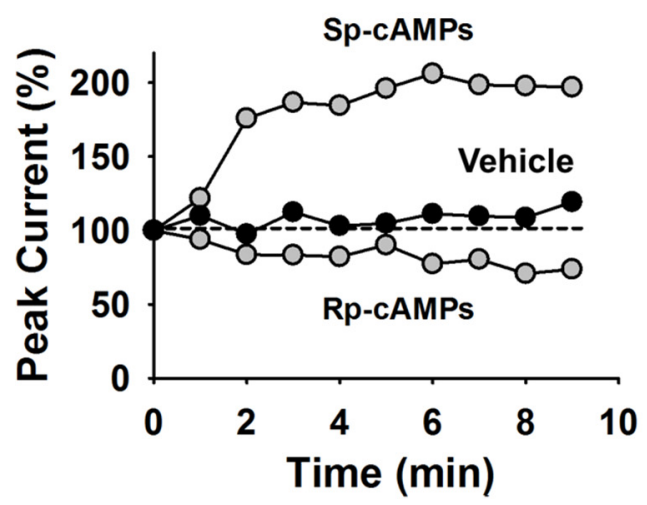

E

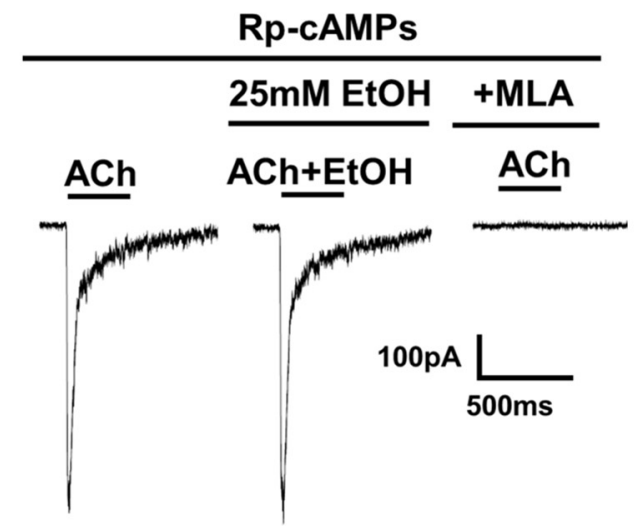

B
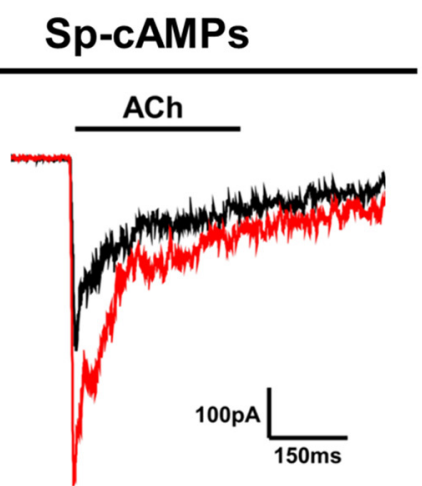

D

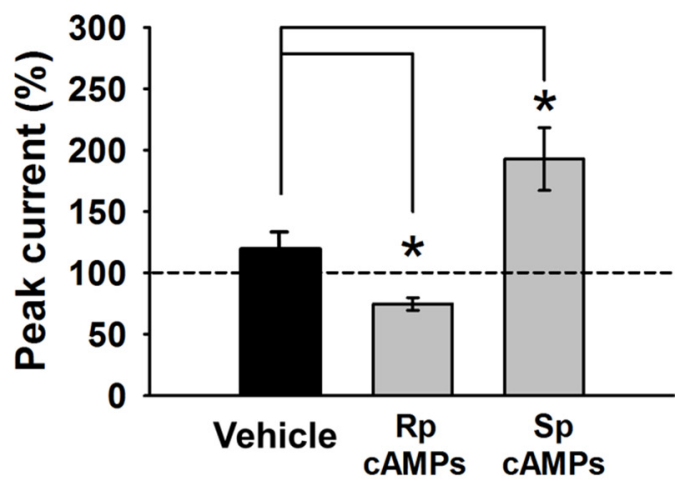

$\mathbf{F}$

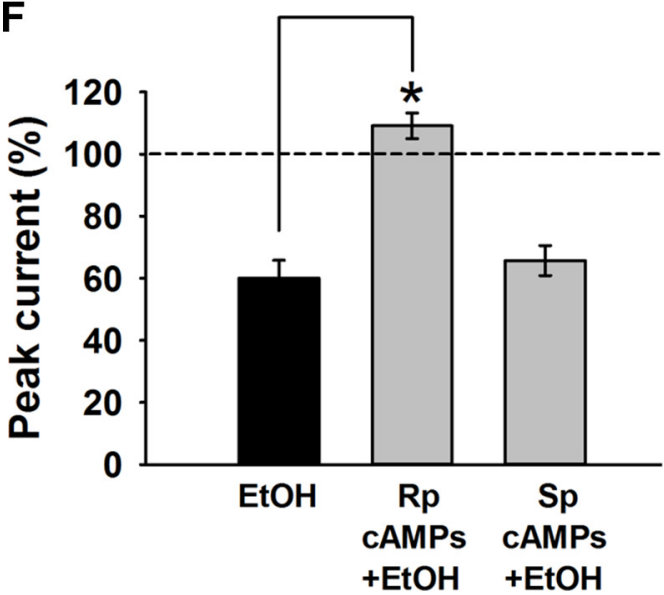

Figure 3. EtOH inhibition of $\alpha 7 \mathrm{nAChR}$ currents in LDTg neurons occurs via inhibition of the PKA pathway. $A$, Sample ACh (1 mm; $300 \mathrm{~ms})$ responses to the first (black) and fifth (red) ACh applications administered at 1 min intervals with the PKA inhibitor Rp-cAMPs (100 $\mu \mathrm{M})$ in the recording pipette. B, Sample ACh responses to the first (black) and fifth (red) ACh applications administered at 1 min intervals with the PKA activator Sp-CAMPs (1 mM) in the recording pipette. C, Representative time course of $\alpha 7$ currents with standard internal solution (Vehicle), Rp-CAMPs, or Sp-CAMPs in the recording pipette. Data from three different cells are illustrated. Current amplitudes were normalized to the first ACh response at the start of the recording. $D$, Summary data for peak current amplitudes normalized to baseline, illustrating that $\alpha 7$ currents were reduced by Rp-cAMPs and increased Sp-cAMPs treatment $\left[\right.$ ANOVA $\left(F_{(2,20)}=19.4\right.$, post hoc tests), $p=0.03$ and $p=0.004$ for Rp-cAMPs and Sp-cAMPs vs vehicle control, respectively]. $n=7,8$, and 5 for vehicle, Rp-cAMPs, and Sp-cAMPs, respectively. E, Sample traces illustrating Et0H modulation of $\alpha 7$ currents is reduced by including the PKA inhibitor Rp-cAMPs $(100 \mu \mathrm{m})$ in the recording electrode. The current was completely blocked by bath application of MLA (10 nM).F, Summary data showing the averaged response magnitudes normalized to baseline after $10 \mathrm{~min}$ of recording and immediately before EtOH application. Including the PKA inhibitor Rp-cAMPs (100 $\mu \mathrm{M})$ in the recording electrode resulted in no inhibition of the $\alpha 7$ response by EtOH ( $25 \mathrm{~mm})$, suggesting that inhibiting PKA activity occluded the EtOH inhibition of $\alpha 7(n=5)$. Including the PKA activator Sp-cAMPs (1 $\mathrm{mm}$ ) augmented the baseline current (see $\boldsymbol{D})$, but application of EtOH inhibited $\alpha 7$ current amplitudes by a similar percentage to that seen with EtOH treatment alone $(n=5) . n=11,5$, and 5 for EtOH control, Rp-cAMPs, and Sp-CAMPs, respectively; ANOVA $\left(F_{(2,20)}=18.9\right.$, post hoc tests), ${ }^{*} p<0.001$ and $p=0.45$ for Rp-cAMPs plus EtOH and Sp-cAMPs plus EtOH versus $25 \mathrm{~mm}$ EtOH, respectively.

bition of PKA with Rp-cAMPs apparently occludes the EtOH effect, whereas even strong activation of the kinase with a high concentration of Sp-cAMPs can be overcome by EtOH treatment. Together, these data suggest that EtOH modulation of $\alpha 7$ responses in LDTg neurons occurs through inhibition of PKA or a downstream target of PKA.
Role of desensitization in $\alpha 7 \mathrm{nAChR}$ modulation by EtOH EtOH inhibition of $\alpha 7 \mathrm{nAChRs} \mathrm{could} \mathrm{occur} \mathrm{by} \mathrm{inhibiting} \mathrm{recep-}$ tor activation kinetics, decreasing receptor conductance, or increasing receptor desensitization. With our drug application method, any of these mechanisms would result in a smaller peak and less charge transfer during ACh application. The positive 
A

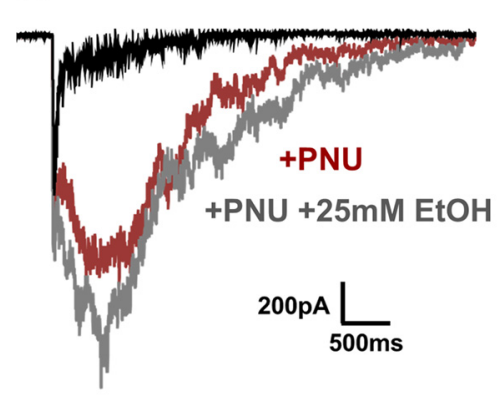

B

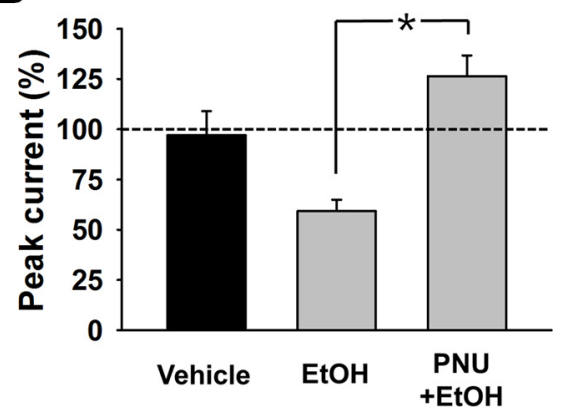

Figure 4. Inhibiting $\alpha 7 \mathrm{nAChR}$ desensitization with PNU120596 blocks the inhibitory effects of EtOH on these receptors. $\boldsymbol{A}$ Representative traces showing that PNU120596, a positive allosteric modulator of the $\alpha 7$ receptor, prolongs receptor activation by interfering with desensitization. Subsequent application of EtOH ( $25 \mathrm{~mm}$ ) did not inhibit $\alpha 7$ currents. $\boldsymbol{B}$, Summary data showing that PNU120596 significantly reduced the inhibitory effect of EtOH on the peak $\alpha 7$ currents. Data are normalized to baseline peak ACh-induced $\alpha 7$ responses. (EtOH alone vs EtOH with PNU, ${ }^{*} p<0.05$ ).

allosteric modulator of $\alpha 7$ nAChRs, PNU120596, decreases receptor desensitization and provides a means of addressing the nature of the EtOH inhibition (Grønlien et al., 2007; Young et al., 2008). Pretreatment of the slice with PNU120596 ( $1 \mu \mathrm{M})$ for 30-40 min before the application of $\mathrm{EtOH}$ dramatically increased the ACh-induced current duration, which is consistent with the predicted change in desensitization (Fig. 4A). Interestingly, PNU120596 pretreatment completely eliminated EtOH inhibition of the $\alpha 7$ nAChR peak current (Fig. $4 B ; n=11$ and 5 for $25 \mathrm{~mm}$ EtOH and PNU120596 plus $25 \mathrm{~mm}$ EtOH, respectively; $\left.t_{(14)}=-6.3, p<0.001\right)$. The PNU120596 pretreatment duration was based on the pretreatment time required to observe the maximal effect on $\alpha 7 \mathrm{nAChR}$ currents without EtOH (data not shown). These data support the idea that EtOH modulates $\alpha 7$ nAChRs in LDTg neurons by enhancing receptor desensitization.

\section{EtOH modulation of presynaptic $\alpha 7 \mathrm{nAChRs}$}

Although EtOH modulates $\alpha 7$ nAChRs on neuronal somata, we were interested in testing whether similar modulation would occur for nAChRs expressed on presynaptic terminals. LDTg neurons project to several thalamic nuclei, including the MD thalamus (Satoh and Fibiger, 1986), which is involved in a range of behaviors including motor control (Swerdlow and Koob, 1987; Churchill et al., 1996; Churchill and Kalivas, 1999). In the presence of bicuculline to block $\mathrm{GABA}_{\mathrm{A}}$-mediated inputs, bath application of nicotine $(1 \mu \mathrm{M})$ increased the frequency of miniature EPSCs (Fig. 5A-C,E), without affecting EPSC amplitude (Fig. $5 D)$, which is consistent with a presynaptic modulation of glutamate transmission. Pretreatment of the slice with MLA (10 nM) inhibited the effects of nicotine on mEPSC frequency, supporting the idea that the nicotine-induced enhancement of glutamate release occurs via presynaptic $\alpha 7$ nAChRs (Fig. $5 F$ ). We then tested EtOH modulation of these presynaptic nAChRs. Pretreating the slices with $\mathrm{EtOH}(25 \mathrm{~mm})$ for 5 min reduced the effect of nicotine on mEPSC frequency (Fig. $5 G$ ). Summary data are presented in Figure $5 H$ (nicotine, $140.2 \pm 6.0 \%$ of baseline, $n=8$; MLA plus nicotine, $90.5 \pm 3.5 \%, n=5$; EtOH plus nicotine, $104.6 \pm 2.2 \%, n=6$; ANOVA, $F_{(2,18)}=8.8, p=0.003$; post hoc test, $p<0.05$ for nicotine plus MLA and nicotine plus EtOH vs nicotine alone). Thus, EtOH inhibits presynaptic $\alpha 7 \mathrm{nAChR}-$ mediated enhancement of the excitatory inputs to MD thalamic neurons.

Role of $\alpha 7$ nAChRs in EtOH-induced motor impairment Motor impairment is a major adverse side effect of EtOH intake. To assess whether the observed effects of EtOH on $\alpha 7 \mathrm{nAChRs}$

could affect motor control, rats were implanted with injection cannulae for focal drug administration into either the cerebral ventricle or the MD thalamus. After recovery, the animals were trained on the accelerating rotarod over a series of 10 consecutive trials, which was sufficient to achieve asymptotic performance, and were then subjected to testing the following day (Fig. 6A). This protocol resulted in a consistent level of baseline performance on the testing day. This challenging motor task was highly sensitive to EtOH injections, with significant impairment observed with doses as low as $1.0 \mathrm{~g} / \mathrm{kg}$. The protocol on testing day consisted of a total of six sets of four consecutive trials, with the first set of trials establishing baseline performance. Animals then received local infusions of vehicle or PNU120596 (100 $\mu \mathrm{M})$, and these were administered either intracerebroventricularly $(20 \mu \mathrm{l})$ or into the MD thalamus $(1 \mu \mathrm{l})$. Then 15 min later, animals in every group received $\mathrm{EtOH}$ injections $(1.0 \mathrm{~g} / \mathrm{kg}$, i.p.). Effects of EtOH on performance were tested in the subsequent five sets of trials at 15 min intervals starting $15 \mathrm{~min}$ after $\mathrm{EtOH}$ injection. For intracerebroventricular injection, in both vehicle- and PNU120596-treated animals, EtOH injection lead to significant impairment of rotarod performance in the first, second, and third trial sets after EtOH injection (Fig. 6B; two-way RM ANOVA, $F_{(5,65)}=24.1, p<0.001$ for effects of time; within-group effects: vehicle, $n=6$, post hoc test, $p<0.05$; PNU120596, $n=5$, post hoc test, $p<0.05)$. Although both groups showed motor impairment, the PNU120596-treated rats were significantly less impaired on the rotarod than vehicle-treated animals ( post hoc test, $p<0.05$ for PNU120596 vs vehicle, within the first and second trial sets after $\mathrm{EtOH}$ injection). As with intracerebroventricular injections, EtOH administration lead to significant motor impairment in animals treated with intra-MD thalamic injections of vehicle or PNU120596 (Fig. 6B; two-way RM ANOVA, $F_{(5,77)}=8.9, p<0.001$ for effects of time; $F_{(1,77)}=$ 5.1, $p<0.05$ for effects over time; vehicle group, $n=6$, post hoc test, $p<0.05$ for first, second, and third trials after EtOH vs baseline, within-group comparison; PNU120596 group, $n=7$, post hoc test, $p<0.05$ for first trial set after EtOH injection vs baseline, within-group comparison). PNU120596-treated animals were significantly less impaired on the rotarod than vehicletreated animals ( $p o s t$ hoc test, $p<0.05$ for PNU120596 vs vehicle, within second and third trial sets after EtOH injection). Together, these results suggest that EtOH inhibition of $\alpha 7 \mathrm{nAChRs}$ in the $\mathrm{MD}$ thalamus contributes to $\mathrm{EtOH}$-induced motor impairment.

\section{EtOH-induced changes in the phosphorylation state of $\alpha 7$ nAChRs}

Phosphorylation state has been reported to modulate nAChR desensitization (Fenster et al., 1999; Swope et al., 1999; Di Angelantonio et al., 2011). To test whether EtOH-induced motor impairment correlates with a change in the phosphorylation state of $\alpha 7 \mathrm{nAChRs}$ in the LDTg, rats received a single injection of either EtOH (1.0 g/kg, i.p.) or PBS. LDTg tissue samples were collected 15 min after EtOH or PBS injection, which is the time point at which the greatest EtOH-induced motor impairment was observed (Fig. 6B). $\alpha 7 \mathrm{nAChR}$ protein was immunoprecipitated, subjected to gel electrophoresis, and then probed on a Western blot for either phosphorylated serine residues or $\alpha 7 \mathrm{nAChR}$ (in 
A

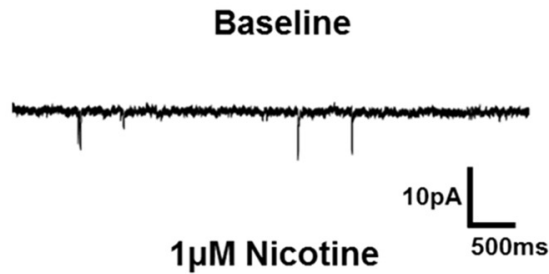

C
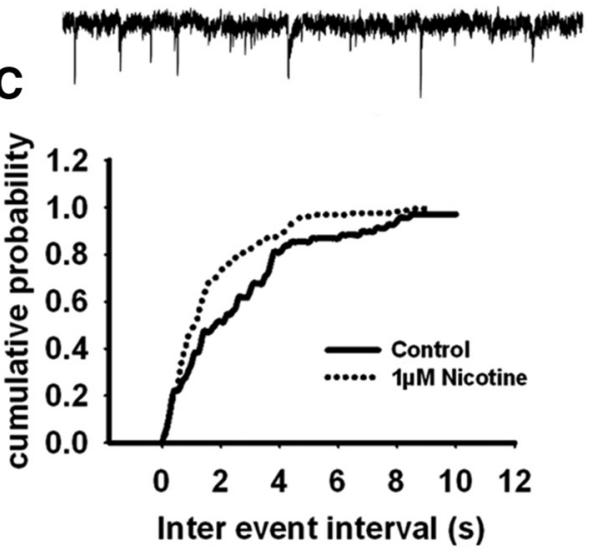

$\mathbf{E}$
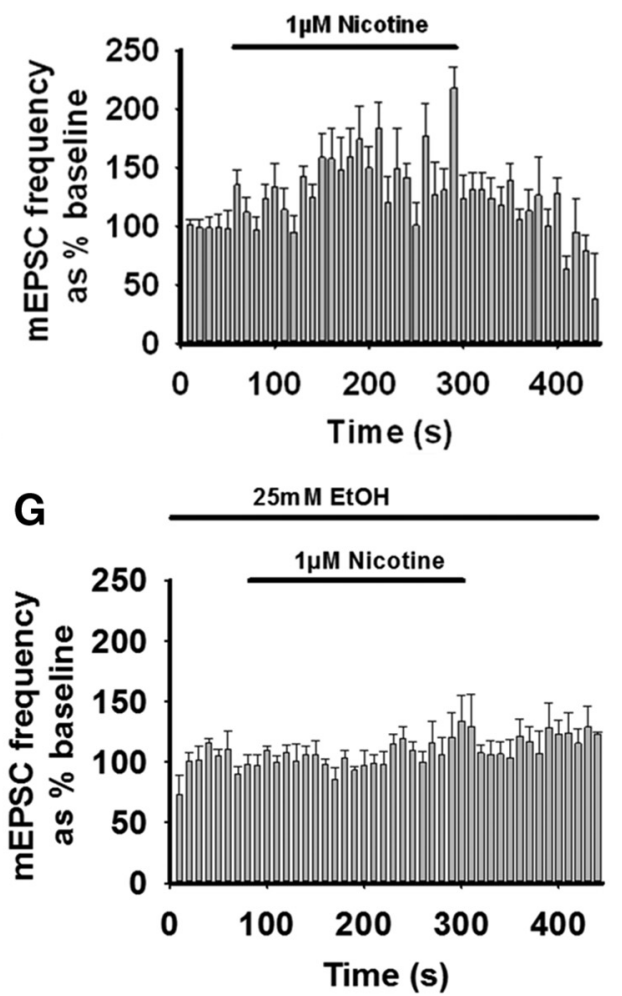

B
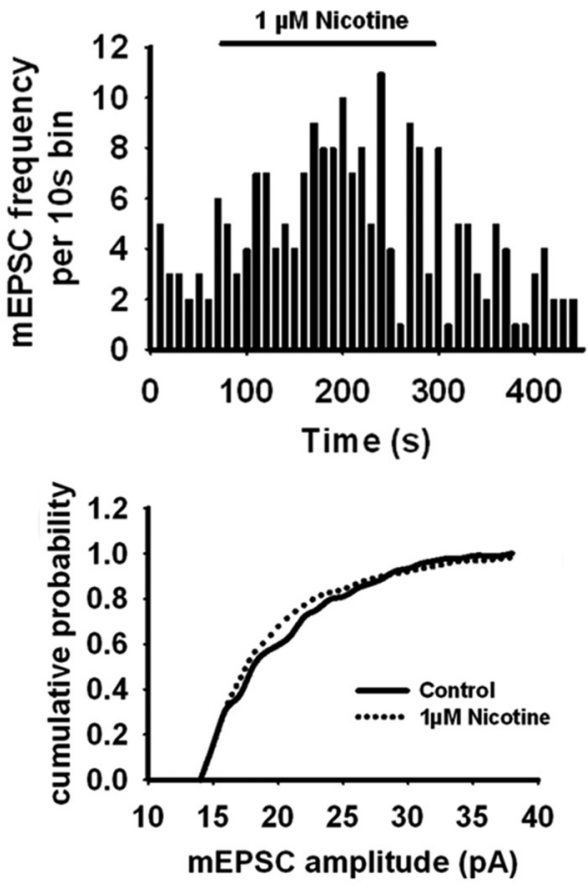

$\mathbf{F}$

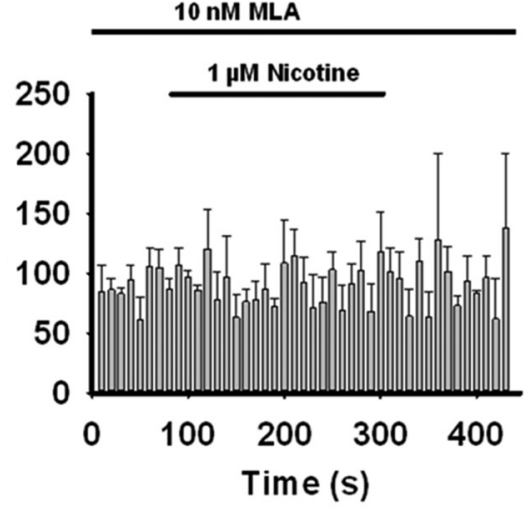

H

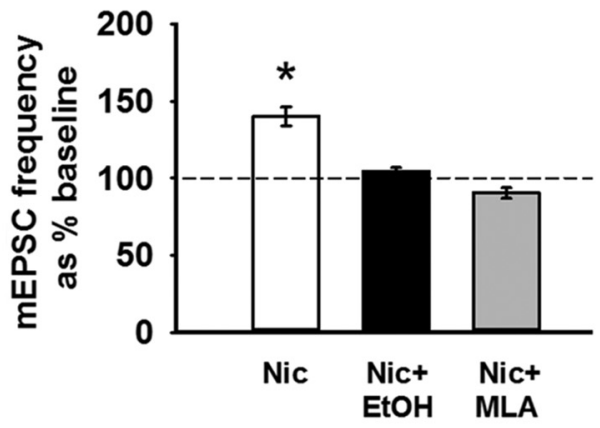

Figure 5. EtOH attenuates nicotine-induced increases in glutamatergic transmission to MD thalamic neurons. $A$, Representative traces showing that bath application of nicotine ( $1 \mu \mathrm{m}$ ) increases the frequency, but not the amplitude, of miniature EPSCs recorded from neurons in the MD thalamus. $\boldsymbol{B}$, Frequency histogram of mEPSCs from a single thalamic neuron recording. C, Cumulative mEPSC frequency distribution for the cell illustrated in $\boldsymbol{A}$ and $\boldsymbol{B}$. Nicotine significantly increased the frequency of mEPSCs ( $p<0.05$ by K-S test). $\boldsymbol{D}$, (umulative $\mathrm{mEPSC}$ amplitude distribution for the cell illustrated in $\boldsymbol{A}$ and $\boldsymbol{B}$. Nicotine did not affect the amplitude of $\mathrm{mEPSCs}$ ( $p>0.05$ by K-S test). $\boldsymbol{E}$, Averaged $\mathrm{mEPSC}$ frequency histogram for all cells tested, normalized to baseline. Nicotine increased the frequency of $\mathrm{mEPSCs}(1 \mu \mathrm{m} ; p<0.05)$. $\boldsymbol{F}$, Averaged mEPSC frequency histogram for all cells tested, normalized to baseline, showing the response to nicotine in the presence of the selective $\alpha 7 \mathrm{nAChR}$ antagonist MLA (10 nM). MLA pretreatment blocked the nicotine-induced increase in mEPSC frequency. $\mathbf{G}$, Averaged mEPSC frequency histogram for all cells tested, normalized to baseline, showing the response to nicotine in the presence of EtOH $(25 \mathrm{~mm})$. EtOH pretreatment blocked the nicotine-induced increase in mEPSC frequency. $\boldsymbol{H}$, Summary data showing that both MLA (10 nM) and EtOH ( $25 \mathrm{~mm})$ blocked the nicotine-induced increase in $\mathrm{mEPSC}$ frequency in MD thalamic neurons. Data are normalized to baseline mEPSC frequency before bath application of nicotine $\left(V_{\mathrm{m}}=-70 \mathrm{mV} ;{ }^{*} p<0.05\right.$ relative to baseline). 

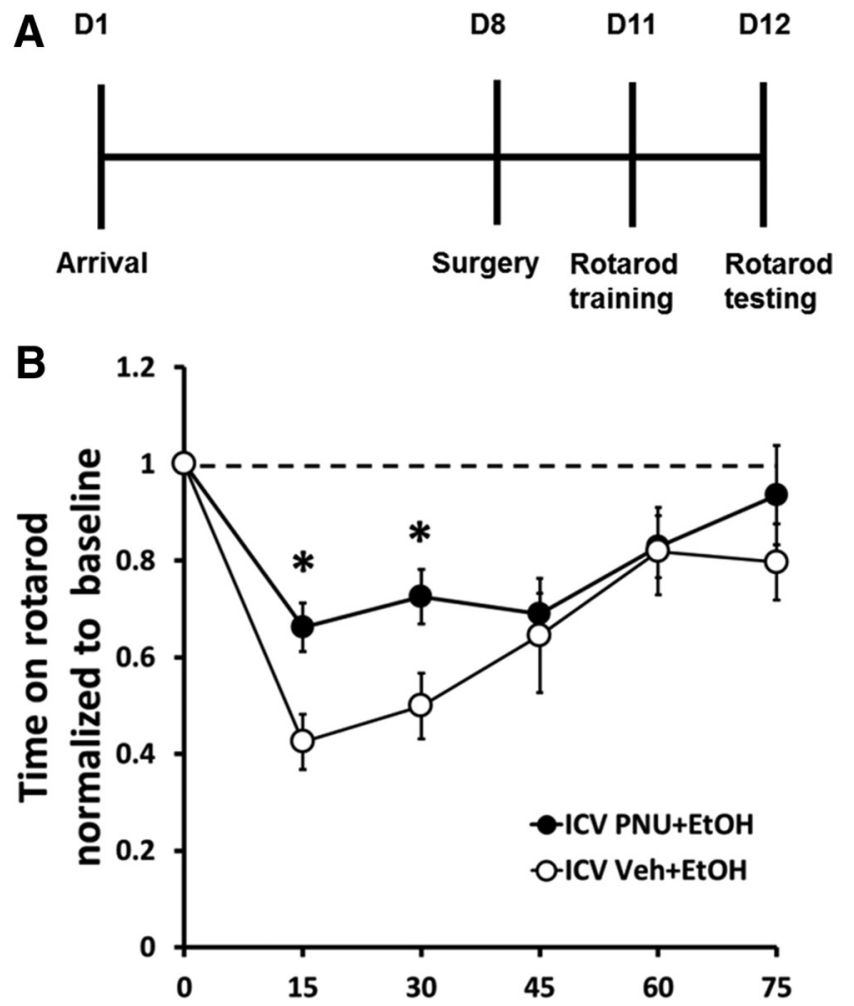

Time $(\mathrm{min})$ after EtOH $(1 \mathrm{~g} / \mathrm{kg})$ injection

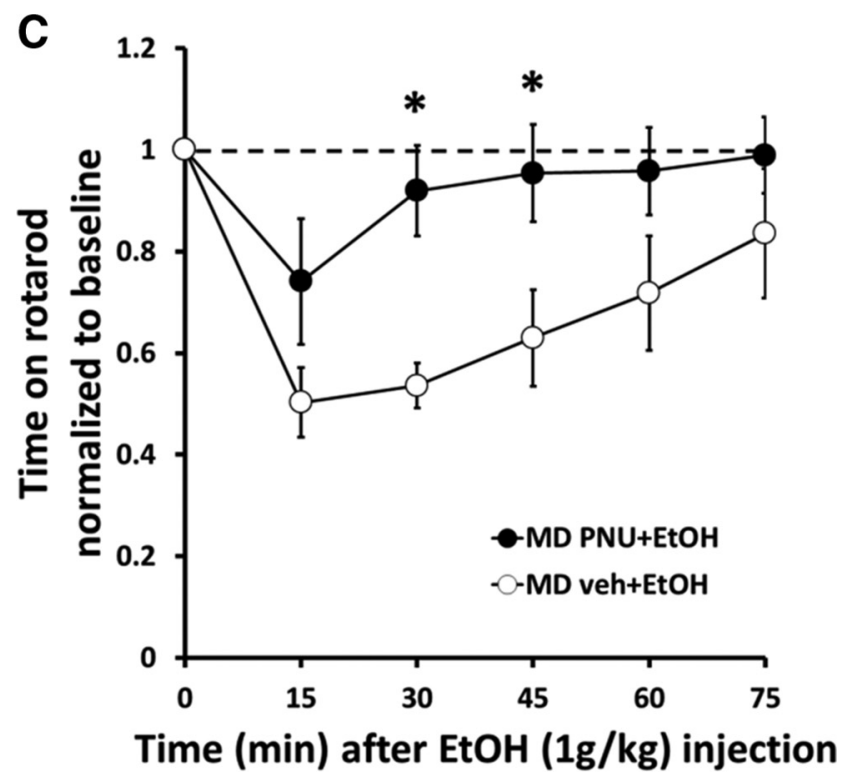

Figure 6. EtOH-induced motor impairment is attenuated by intracerebroventricular or intra-MD thalamic injection of PNU120596. $\boldsymbol{A}$, Diagram of the timeline for the behavioral studies. $\boldsymbol{B}$, Animals previously trained on the accelerating rotarod were first tested for baseline performance with a set of four trials. The times to fall from the rod were averaged within and then between animals in each group to yield group mean performance values. The rats then received intracerebroventricular injections of either vehicle or PNU120596 (20 $\mu \mathrm{l}, 100 \mu \mathrm{m})$, followed $15 \mathrm{~min}$ later by an intraperitoneal injection of EtOH $(1 \mathrm{~g} / \mathrm{kg})$ and five sets of four trials on the rotarod. Both vehicle- and PNU120596-treated rats showed marked motor impairment after EtOH administration, but PNU120596-treated animals showed less impairment compared with vehicle $\left({ }^{*} p<0.05\right.$ ). The rate of performance recovery after EtOH treatment was similar between these groups. PNU120596 treatment in the absence of EtOH had no effect on motor performance (data not shown). $\boldsymbol{C}$, Another group of animals was treated exactly the same as in $\boldsymbol{B}$, but they received intra-MD thalamic injections of either vehicle or PNU120596 (1 $\mu$ l, $100 \mu \mathrm{m})$. After EtOH injection $(1 \mathrm{~g} / \mathrm{kg}$ ) both vehicle and PNU120596-treated rats showed separate immunoblots). Each gel was loaded in the same order with samples from the same homogenate, and samples from both treatment groups were run on the same gel to allow for within-gel comparison. We observed strong immunoreactivity for phosphoserine at the same molecular weight as $\alpha 7 \mathrm{nAChR}$ subunit (56 $\mathrm{kDa}$ ), which likely reflects phosphorylated serine residues on $\alpha 7$ nAChRs (Fig. 7A). The phosphorylation state was calculated as the ratio of phosphoserine immunoreactivity/ $\alpha 7 \mathrm{nAChR}$ immunoreactivity from the same sample. The ratios were then normalized to the average of the ratios for the saline control group. Relative to the saline control group $(n=6)$, average ratio of phosphoserine/ $\alpha 7 \mathrm{nAChR}$ immunoreactivity in the EtOH treatment group was $0.86 \pm 0.07$ (Fig. $7 B ; n=5$, Student's $t$ test, $t_{(9)}=$ 3.6, $p=0.005)$. This indicates that a single injection of EtOH ( $1 \mathrm{~g} / \mathrm{kg}$, i.p.) decreases the phosphorylation state of serine residues on LDTg $\alpha 7 \mathrm{nAChRs}$ in vivo, which is consistent with our hypothesis that EtOH inhibits the PKA pathway to modulate $\alpha 7$ function.

\section{Discussion}

Our findings support the idea that $\alpha 7 \mathrm{nAChRs}$ are an important target for EtOH-mediated motor impairment (Fig. 8). In recordings from LDTg neurons, we show that EtOH suppresses $\alpha 7 \mathrm{nAChR}$ currents by enhancing receptor desensitization in a PKA-dependent manner. Inhibition of PKA suppresses $\alpha 7$ currents and occludes the modulatory effects of EtOH on these receptors. Activating this pathway enhances $\alpha 7$ $\mathrm{nAChR}$ responses and had no effect on the modulation by EtOH. Interfering with desensitization of $\alpha 7 \mathrm{nAChRs}$ with the positive allosteric modulator PNU120596 prevents the EtOHinduced decrease in $\alpha 7$ current amplitude. In behavioral studies, administering PNU120596 directly into the cerebral ventricles reduces $\mathrm{EtOH}$-induced impairment of motor performance. In vivo EtOH administration reduced the phosphorylation state of $\alpha 7$ subunit protein, which may mediate the physiological and behavioral changes observed. Thus, we present a novel modulatory effect of EtOH on $\alpha 7 \mathrm{nAChRs}$ in the brain, and preventing this effect decreases EtOH impairment of motor performance.

The focal application system used in our studies is particularly sensitive to changes in receptor desensitization. The arrival of $\mathrm{ACh}$ at the membrane during pressure application is slow (20$200 \mathrm{~ms}$ ) relative to synaptic transmission or rapid perfusion systems with isolated cells. This is attributable to diffusion barriers in the brain slice and cell geometry. As such, the onset of the ACh-induced current reflects a combination of receptor activation and desensitization, and both of these parameters affect the peak current. Our within-cell design helps limit confounds associated with differences in drug application between cells. Even with that strong experimental design, it is possible that EtOH modulation of these responses influences receptor activation kinetics or other properties that our methods may not resolve. However, it is important to emphasize that we observed no inhibitory effect of EtOH in the presence of the allosteric modulator PNU120596, which is consistent with our interpretation that en-

$\leftarrow$

marked motor impairment after administration of EtOH. However, PNU120596-treated animals showed significantly less impairment of rotarod performance compared with vehicle-treated rats $\left({ }^{*} p<0.05\right)$. The rate of performance recovery after EtOH treatment was similar between these groups. PNU120596 treatment in the absence of EtOH had no effect on motor performance (data not shown). 
A

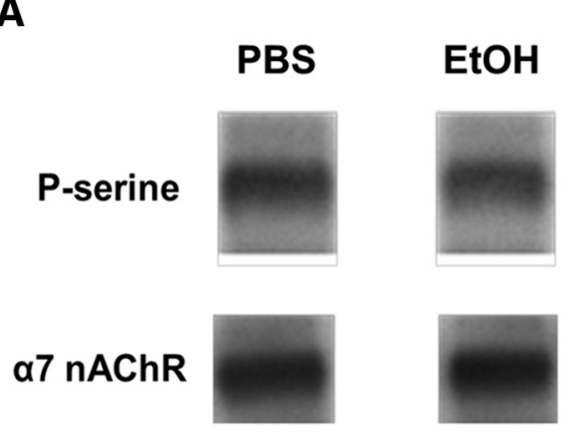

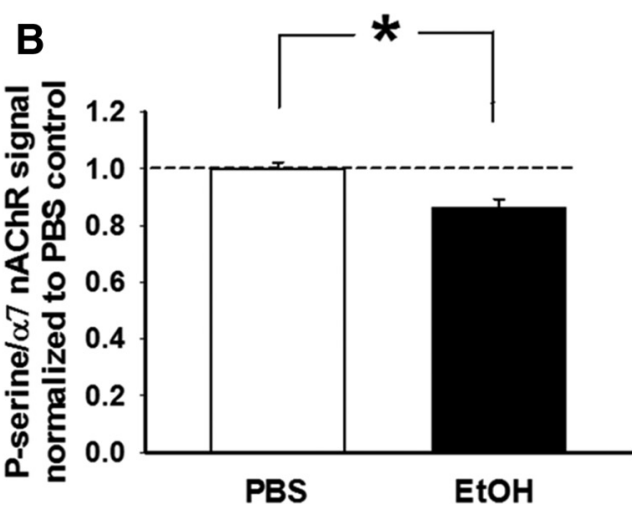

Figure 7. EtOH decreases the phosphorylation of $\alpha 7 \mathrm{nAChRs}$ in the LDTg. $\boldsymbol{A}$, Representative immunoblots show immunoreactive bands for phosphoserine (P-serine) residues and $\alpha 7$ nAChR subunits. LDTg tissue samples were collected $15 \mathrm{~min}$ after rats were pretreated with either EtOH $(1.0 \mathrm{~g} / \mathrm{kg}$, i.p.) or PBS (intraperitoneally), homogenized, and subjected to immunoprecipitation with anti- $\alpha 7$ antibodies. The phosphorylation state of LDTg $\alpha 7 \mathrm{nAChRs}$ was calculated as the ratio of P-serine $/ \alpha 7 \mathrm{nAChR}$ signal normalized to control (PBS). $\boldsymbol{B}$, Bar graph illustrates that EtOH decreases the phosphorylation state of LDTg $\alpha 7$ nAChRs in vivo $\left({ }^{*} p<0.01\right)$.

hanced desensitization is an important, if not the sole mediator of $\mathrm{EtOH}$ inhibition of $\alpha 7$ nAChRs.

\section{Role of PKA in EtOH effects on $\alpha 7$ nAChRs and motor impairment} Phosphorylation state is known to modulate the function of many ligand-gated ion channels (Fenster et al., 1999; Swope et al., 1999; Di Angelantonio et al., 2011). Our study is the first to establish a link between PKA phosphorylation and $\alpha 7$ receptor function. Previous studies have established that PKA phosphorylates the intracellular domain of $\alpha 7 \mathrm{nAChR}$ subunits (Moss et al., 1996), and our data suggest that this posttranslational modification alters receptor desensitization. We contend that EtOH inhibits cAMP/PKA signaling, leading to inhibition of $\alpha 7$ currents by enhancing the rapid desensitization characteristic of these receptors. This idea is supported by our finding that PNU120596, which interferes with $\alpha 7$ nAChR desensitization (Hurst et al., 2005), prevents EtOHinduced inhibition of $\alpha 7$ currents. This model is further supported by the decrease in phosphorylation state of the $\alpha 7$ subunit protein in LDTg of EtOH-treated rats.

The modulation of $\alpha 7 \mathrm{nAChR}$ responses by EtOH was not observed with simultaneous coapplication of $\mathrm{ACh}$ and $\mathrm{EtOH}$ in the same pipette, which led us to explore indirect inhibition of $\alpha 7$ currents via PKA signaling. Although our data support this model, an alternate interpretation is that a phosphorylation state-dependent direct interaction is occurring, albeit with slower kinetics than ACh-induced activation. One argument against this idea is that it would predict a stronger EtOHinduced inhibition of $\alpha 7$ currents when Sp-cAMPs is present in the recording pipette, because more of the receptors would presumably be phosphorylated and thus able to be inhibited by EtOH. The data showed no difference in the percentage inhibition of the peak current under these conditions. Additionally, Rp-cAMPs occluded the inhibitory effect of EtOH and inhibited the $\alpha 7$ current independent of EtOH. This suggests that decreased PKA activity is sufficient to inhibit $\alpha 7$ - mediated currents on its own and that some baseline PKA activity is necessary to allow EtOH-induced inhibition of $\alpha 7$ currents. As allosteric proteins, $\alpha 7 \mathrm{nAChR}$ function can be modified in a variety of interesting ways, and future studies will be required to completely resolve the underlying molecular interactions.

Previous biochemical studies support the idea that EtOH can decrease cAMP and presumably PKA activity (Nagy and DeSilva, 1992). There are also reports that EtOH can activate adenylyl cyclase; however, those studies used a substantially higher EtOH concentration $(100 \mathrm{~mm})$ than those used in our electrophysiological and behavioral investigations (10-50 mM; Rabin and Molinoff, 1981; Hellevuo et al., 1995; Yoshimura and Tabakoff, 1999). Additional support for our findings has linked reduced cAMP/PKA to the sedative effects of EtOH. Mice with constitutively active PKA show decreased EtOH-induced sedation and enhanced EtOH self-administration (Thiele et al., 2000). Together with our results, these findings suggest that PKA activity can modify the sedative/motor impairing effects of EtOH, which may influence $\mathrm{EtOH}$ self-administration. 


\section{Implications of EtOH effects on $\alpha 7 \mathrm{nAChR}$ function}

EtOH inhibition of $\alpha 7 \mathrm{nAChRs} \mathrm{via} \mathrm{cAMP/PKA} \mathrm{likely} \mathrm{affects} \mathrm{neu-}$ ronal excitability and synaptic plasticity in a number of different brain areas. We have shown that EtOH inhibits somatic $\alpha 7$ nAChRs in LDTg neurons and blocks the effects of nicotine on presynaptic $\alpha 7 \mathrm{nAChRs}$ in the MD thalamus (Fig. 7). A substantial proportion of LDTg cholinergic neurons project to the thalamus (Oakman et al., 1999; Holmstrand and Sesack, 2011), and our data reveal presynaptic $\alpha 7 \mathrm{nAChRs}$ on glutamatergic inputs to the thalamus. Therefore, the effect of EtOH suppression of $\alpha 7$ nAChRs on this motor control pathway is twofold: (1) by reducing ACh release through suppression of LDTg neuron excitability; and (2) by inhibiting presynaptic $\alpha 7 \mathrm{nAChR}$-mediated enhancement of glutamate release in thalamus (Fig. 8). Therefore, the combined effects would reduce both glutamatergic and cholinergic tone, thereby decreasing excitability in the thalamus. Although it remains to be demonstrated that the cAMP/PKA system underlies the EtOH modulation of presynaptic $\alpha 7$ receptors, adenylyl cyclase and PKA are expressed in axon terminals where they can modulate synaptic transmission (Byrne and Kandel 1996; Trudeau et al. 1996). It is likely that $\alpha 7$ phosphorylation state via PKA is a mediator of EtOH modulation of glutamate release in thalamus. It will also be interesting to explore the effect of these modulatory mechanisms on other motor control circuitry that may contribute to the motor-impairing effects of EtOH.

Similar mechanisms may also contribute to EtOH-induced changes in reward circuitry. Other nAChR subtypes can show enhanced receptor function in the presence of $\mathrm{EtOH}$, and recent studies have implicated $\alpha 6$ subunit as a potentially important target in for EtOH-induced increased neuronal excitability in reward pathways (Liu et al., 2013a,b). The EtOH-induced suppression of $\alpha 7$ currents may also modify reward pathways, but this remains to be investigated.

\section{Implications for pharmacology of EtOH motor impairment}

In alcohol-related automobile accidents that result in fatalities, $18 \%$ of impaired drivers had blood alcohol levels below the legal driving limit (NHTSA, 2007). This suggests that significant motor impairment can result from blood EtOH levels below $17.4 \mathrm{~mm}$ (0.08\%; Yoshimoto and Komura, 1993; Adalsteinsson et al., 2006), which is the legal limit for driving in most states. Blood alcohol levels as low as $8 \mathrm{~mm}$ can result in impaired performance during driving simulations (Banks et al., 2004). Similarly low EtOH concentrations in rats impair postural control and decrease performance on the accelerating rotarod (Mangold et al., 1996; Palm et al., 2010). Thus, both rats and humans experience EtOH-induced motor impairment at similar blood levels, which supports the relevance of the present study to EtOH effects in humans.

The present study illustrates that a low, behaviorally relevant dose of EtOH also results in significant molecular and cellular effects. These EtOH concentrations cause inhibition of $\alpha 7$ nAChRs in the LDTg and presynaptically in the motor relay centers in the thalamus. The effect of intracerebroventricular or intra-MD thalamic PNU120596 on EtOH-induced motor impairment strengthens the argument that $\alpha 7 \mathrm{nAChRs} \mathrm{specifically}$ are involved in this behavioral effect. It is important to note that $\alpha 7 \mathrm{nAChRs}$ are expressed in many brain regions both somatically and presynaptically, but the current data indicate a possible role for presynaptic $\alpha 7 \mathrm{nAChRs}$ in the MD thalamus in the effects of $\mathrm{EtOH}$ on motor performance. However, our data also show a strong interaction between EtOH and $\alpha 7 \mathrm{nAChRs}$ in the LDTg, an area known to be involved in a variety of behaviors, including motor control (Laviolette et al., 2000; Kayama and Koyama, 2003; Alderson et al., 2005; Maskos, 2008).

This study highlights the potential importance of nicotinic receptors, particularly the $\alpha 7$ subtype, in the effects of EtOH on motor performance. Our results have identified novel targets to limit or suppress $\mathrm{EtOH}$-induced motor impairment. Additional investigation may identify novel treatments to address the public health problems associated with EtOH abuse. Additionally, the contribution of these targets to the co-abuse of nicotine and EtOH should be tested, and improved understanding may help identify new strategies to treat these addictions.

\section{References}

Adalsteinsson E, Sullivan EV, Mayer D, Pfefferbaum A (2006) In vivo quantification of ethanol kinetics in rat brain. Neuropsychopharmacology 31: 2683-2691. CrossRef Medline

Aistrup GL, Marszalec W, Narahashi T (1999) Ethanol modulation of nicotinic acetylcholine receptor currents in cultured cortical neurons. Mol Pharmacol 55:39-49. Medline

Alderson HL, Latimer MP, Winn P (2005) Involvement of the laterodorsal tegmental nucleus in the locomotor response to repeated nicotine administration. Neurosci Lett 380:335-339. CrossRef Medline

Al-Rejaie S, Dar MS (2006) Antagonism of ethanol ataxia by intracerebellar nicotine: possible modulation by mouse cerebellar nitric oxide and cGMP. Brain Res Bull 69:187-196. CrossRef Medline

Azam L, Winzer-Serhan U, Leslie FM (2003) Co-expression of alpha7 and beta2 nicotinic acetylcholine receptor subunit mRNAs within rat brain cholinergic neurons. Neuroscience 119:965-977.

Banks S, Catcheside P, Lack L, Grunstein RR, McEvoy RD (2004) Low levels of alcohol impair driving simulator performance and reduce perception of crash risk in partially sleep deprived subjects. Sleep 27:1063-1067. Medline

Barrett SP, Tichauer M, Leyton M, Pihl RO (2006) Nicotine increases alcohol self-administration in non-dependent male smokers. Drug Alcohol Depend 81:197-204. CrossRef Medline

Bennett C, Arroyo S, Berns D, Hestrin S (2012) Mechanisms generating dual-component nicotinic EPSCs in cortical interneurons. J Neurosci 32:17287-17296.

Blomqvist O, Ericson M, Johnson DH, Engel JA, Söderpalm B (1996) Voluntary ethanol intake in the rat: effects of nicotinic acetylcholine receptor blockade or subchronic nicotine treatment. Eur J Pharmacol 314: 257-267. CrossRef Medline

Bowers BJ, McClure-Begley TD, Keller JJ, Paylor R, Collins AC, Wehner JM (2005) Deletion of the alpha7 nicotinic receptor subunit gene results in increased sensitivity to several behavioral effects produced by alcohol. Alcohol Clin Exp Res 29:295-302. CrossRef Medline

Byrne JH, Kandel ER (1996) Presynaptic facilitation revisited: state and time dependence. J Neurosci 16:425-435. Medline

Cardoso RA, Brozowski SJ, Chavez-Noriega LE, Harpold M, Valenzuela CF, Harris RA (1999) Effects of ethanol on recombinant human neuronal nicotinic acetylcholine receptors expressed in Xenopus oocytes. J Pharmacol Exp Ther 289:774-780. Medline

CASA (2007) Tobacco: the smoking gun. New York: National Center on Addiction and Substance Abuse at Columbia University.

Chilton M, Mastropaolo J, Rosse RB, Bellack AS, Deutsch SI (2004) Behavioral consequences of methyllycaconitine in mice: a model of alpha7 nicotinic acetylcholine receptor deficiency. Life Sci 74:3133-3139. CrossRef Medline

Churchill L, Kalivas PW (1999) The involvement of the mediodorsal nucleus of the thalamus and the midbrain extrapyramidal area in locomotion elicited from the ventral pallidum. Behav Brain Res 104:63-71. CrossRef Medline

Churchill L, Zahm DS, Duffy P, Kalivas PW (1996) The mediodorsal nucleus of the thalamus in rats-II. Behavioral and neurochemical effects of GABA agonists. Neuroscience 70:103-112. CrossRef Medline

Covernton PJ, Connolly JG (1997) Differential modulation of rat neuronal nicotinic receptor subtypes by acute application of ethanol. Br J Pharmacol 122:1661-1668. CrossRef Medline

Di Angelantonio S, Piccioni A, Moriconi C, Trettel F, Cristalli G, Grassi F, Limatola C (2011) Adenosine A2A receptor induces protein kinase 
A-dependent functional modulation of human (alpha)3(beta) 4 nicotinic receptor. J Physiol 589:2755-2766. CrossRef Medline

Fenster CP, Beckman ML, Parker JC, Sheffield EB, Whitworth TL, Quick MW, Lester RA (1999) Regulation of alpha4beta2 nicotinic receptor desensitization by calcium and protein kinase C. Mol Pharmacol 55: 432-443. Medline

Frazier CJ, Buhler AV, Weiner JL, Dunwiddie TV (1998) Synaptic potentials mediated via alpha-bungarotoxin-sensitive nicotinic acetylcholine receptors in rat hippocampal interneurons. J Neurosci 18:8228-8235.

Grønlien JH, Håkerud M, Ween H, Thorin-Hagene K, Briggs CA, Gopalakrishnan M, Malysz J (2007) Distinct profiles of alpha7 nAChR positive allosteric modulation revealed by structurally diverse chemotypes. Mol Pharmacol 72:715-724. CrossRef Medline

Hellevuo K, Yoshimura M, Mons N, Hoffman PL, Cooper DM, Tabakoff B (1995) The characterization of a novel human adenylyl cyclase which is present in brain and other tissues. J Biol Chem 270:1158111589. CrossRef Medline

Holmstrand EC, Sesack SR (2011) Projections from the rat pedunculopontine and laterodorsal tegmental nuclei to the anterior thalamus and ventral tegmental area arise from largely separate populations of neurons. Brain Struct Funct 216:331-345. CrossRef Medline

Hurst RS, Hajos M, Raggenbass M, Wall TM, Higdon NR, Lawson JA, Rutherford-Root KL, Berkenpas MB, Hoffmann WE, Piotrowski DW, Groppi VE, Allaman G, Ogier R, Bertrand S, Bertrand D, Arneric SP (2005) A novel positive allosteric modulator of the alpha7 neuronal nicotinic acetylcholine receptor: in vitro and in vivo characterization. J Neurosci 25:4396-4405. CrossRef Medline

Ishibashi M, Leonard CS, Kohlmeier KA (2009) Nicotinic activation of laterodorsal tegmental neurons: implications for addiction to nicotine. Neuropsychopharmacology 34:2529-2547. CrossRef Medline

Jiang L, Role LW (2008) Facilitation of cortico-amygdala synapses by nicotine: activity-dependent modulation of glutamatergic transmission. J Neurophysiol 99:1988-1999. CrossRef Medline

Kayama Y, Koyama Y (2003) Control of sleep and wakefulness by brainstem monoaminergic and cholinergic neurons. Acta Neurochir Suppl 87:3-6. Medline

Kempsill FE, PrattJA (2000) Mecamylamine but not the alpha7 receptor antagonist alpha-bungarotoxin blocks sensitization to the locomotor stimulant effects of nicotine. Br J Pharmacol 131:997-1003. CrossRef Medline

Laviolette SR, Priebe RP, Yeomans JS (2000) Role of the laterodorsal tegmental nucleus in scopolamine- and amphetamine-induced locomotion and stereotypy. Pharmacol Biochem Behav 65:163-174. CrossRef Medline

Liu L, Zhao-Shea R, McIntosh JM, Tapper AR (2013a) Nicotinic acetylcholine receptors containing the alpha6 subunit contribute to ethanol activation of ventral tegmental area dopaminergic neurons. Biochem Pharmacol 86:1194-1200. CrossRef Medline

Liu L, Hendrickson LM, Guildford MJ, Zhao-Shea R, Gardner PD, Tapper AR (2013b) Nicotinic acetylcholine receptors containing the alpha4 subunit modulate alcohol reward. Biol Psychiatry 73:738-746. CrossRef Medline

Mangold S, Läubli T, Krueger H (1996) Effects of a low alcohol dose on static balance, fine motor activity, and mental performance. Neurotoxicol Teratol 18:547-554. CrossRef Medline

Mansvelder HD, McGehee DS (2000) Long-term potentiation of excitatory inputs to brain reward areas by nicotine. Neuron 27:349-357. CrossRef Medline

Marks MJ, Burch JB, Collins AC (1983) Effects of chronic nicotine infusion on tolerance development and nicotinic receptors. J Pharmacol Exp Ther 226:817-825. Medline

Maskos U (2008) The cholinergic mesopontine tegmentum is a relatively neglected nicotinic master modulator of the dopaminergic system: relevance to drugs of abuse and pathology. Br J Pharmacol 153 [Suppl 1]: S438-S445. CrossRef Medline

McGehee DS, Heath MJ, Gelber S, Devay P, Role LW (1995) Nicotine enhancement of fast excitatory synaptic transmission in CNS by presynaptic receptors. Science 269:1692-1696. CrossRef Medline

Miller NS, Gold MS (1998) Comorbid cigarette and alcohol addiction: epidemiology and treatment. J Addict Dis 17:55-66. Medline

Moss SJ, McDonald BJ, Rudhard Y, Schoepfer R (1996) Phosphorylation of the predicted major intracellular domains of the rat and chick neuronal nicotinic acetylcholine receptor alpha 7 subunit by cAMP-dependent protein kinase. Neuropharmacology 35:1023-1028. CrossRef Medline
Nagy LE, DeSilva SE (1992) Ethanol increases receptor-dependent cyclic AMP production in cultured hepatocytes by decreasing G(i)-mediated inhibition. Biochem J 286:681-686. Medline

NHTSA (2007) Alcohol impaired driving fatalities. Washington, DC: National Highway Traffic Safety Administration.

Oakman SA, Faris PL, Cozzari C, Hartman BK (1999) Characterization of the extent of pontomesencephalic cholinergic neurons' projections to the thalamus: comparison with projections to midbrain dopaminergic groups. Neuroscience 94:529-547. CrossRef Medline

O’Brien MC, McCoy TP, Rhodes SD, Wagoner A, Wolfson M (2008) Caffeinated cocktails: energy drink consumption, high-risk drinking, and alcohol-related consequences among college students. Acad Emerg Med 15:453-460. CrossRef Medline

Oz M, Jackson SN, Woods AS, Morales M, Zhang L (2005) Additive effects of endogenous cannabinoid anandamide and ethanol on alpha7-nicotinic acetylcholine receptor-mediated responses in Xenopus oocytes. J Pharmacol Exp Ther 313:1272-1280. CrossRef Medline

Palm HG, Waitz O, Strobel J, Metrikat J, Hay B, Friemert B (2010) Effects of low-dose alcohol consumption on postural control with a particular focus on the role of the visual system. Motor Control 14:265-276. Medline

Paxinos G, Watson C (1998) The rat brain in stereotaxic coordinates, Ed 4. San Diego: Academic.

Quik M, Philie J, Choremis J (1997) Modulation of alpha7 nicotinic receptor-mediated calcium influx by nicotinic agonists. Mol Pharmacol 51:499-506. Medline

Rabin RA, Molinoff PB (1981) Activation of adenylate cyclase by ethanol in mouse striatal tissue. J Pharmacol Exp Ther 216:129-134. Medline

Radcliffe KA, Fisher JL, Gray R, Dani JA (1999) Nicotinic modulation of glutamate and GABA synaptic transmission of hippocampal neurons. Ann NY Acad Sci 868:591-610. CrossRef Medline

Satoh K, Fibiger HC (1986) Cholinergic neurons of the laterodorsal tegmental nucleus: efferent and afferent connections. J Comp Neurol 253: 277-302. CrossRef Medline

Séguéla P, Wadiche J, Dineley-Miller K, Dani JA, Patrick JW (1993) Molecular cloning, functional properties, and distribution of rat brain alpha 7: a nicotinic cation channel highly permeable to calcium. J Neurosci 13: 596-604. Medline

Swerdlow NR, Koob GF (1987) Lesions of the dorsomedial nucleus of the thalamus, medial prefrontal cortex and pedunculopontine nucleus: effects on locomotor activity mediated by nucleus accumbens-ventral pallidal circuitry. Brain Res 412:233-243. CrossRef Medline

Swope SL, Moss SJ, Raymond LA, Huganir RL (1999) Regulation of ligandgated ion channels by protein phosphorylation. Adv Second Messenger Phosphoprotein Res 33:49-78. CrossRef Medline

Thiele TE, Willis B, Stadler J, Reynolds JG, Bernstein IL, McKnight GS (2000) High ethanol consumption and low sensitivity to ethanol-induced sedation in protein kinase A-mutant mice. J Neurosci 20:RC75. Medline

Trudeau LE, Emery DG, Haydon PG (1996) Direct modulation of the secretory machinery underlies PKA-dependent synaptic facilitation in hippocampal neurons. Neuron 17:789-797. CrossRef

Welch KD, Pfister JA, Lima FG, Green BT, Gardner DR (2013) Effect of alpha(7) nicotinic acetylcholine receptor agonists and antagonists on motor function in mice. Toxicol Applied Pharmacol 266:366-374. CrossRef Medline

Welsby P, Rowan M, Anwyl R (2006) Nicotinic receptor-mediated enhancement of long-term potentiation involves activation of metabotropic glutamate receptors and ryanodine-sensitive calcium stores in the dentate gyrus. Eur J Neurosci 24:3109-3118. CrossRef Medline

Yoshimoto K, Komura S (1993) Monitoring of ethanol levels in the rat nucleus accumbens by brain microdialysis. Alcohol Alcohol 28:171-174. Medline

Yoshimura M, Tabakoff B (1999) Ethanol's actions on cAMP-mediated signaling in cells transfected with type VII adenylyl cyclase. Alcohol Clin Exp Res 23:1457-1461. CrossRef Medline

Young GT, Zwart R, Walker AS, Sher E, Millar NS (2008) Potentiation of alpha7 nicotinic acetylcholine receptors via an allosteric transmembrane site. Proc Natl Acad Sci U S A 105:14686-14691. CrossRef Medline

Yu D, Zhang L, Eiselé JL, Bertrand D, Changeux JP, Weight FF (1996) Ethanol inhibition of nicotinic acetylcholine type alpha 7 receptors involves the amino-terminal domain of the receptor. Mol Pharmacol 50:1010-1016. Medline 